\title{
The role of the cGMP-dependent protein kinase in development of the malaria parasite
} Louisa McRobert ${ }^{1}$, Helen M Taylor ${ }^{2}$, Cathy J Taylor ${ }^{1}$, Wensheng Deng ${ }^{1}$, Robert W Moon ${ }^{3,4}$, Quinton L Fivelman ${ }^{1}$, Munira Grainger ${ }^{3}$, Spencer D Polley ${ }^{1}$, Audrey Sicard ${ }^{2}$, Oliver Billker ${ }^{4}$, Anthony A Holder ${ }^{3}$ and David A Baker*1

Address: ${ }^{1}$ London School of Hygiene \& Tropical Medicine, Keppel Street, London WC1E 7HT, UK, ${ }^{2}$ Wellcome Centre for Molecular Parasitology, University of Glasgow, Glasgow, G12 8TA, UK, ${ }^{3}$ Medical Research Council National Institute for Medical Research, Mill Hill, London NW7 1AA, UK and ${ }^{4}$ Wellcome Trust Sanger Institute, Cambridge Hinxton, CB10 1SA, UK

Email: David A Baker* - david.baker@lshtm.ac.uk

* Corresponding author

from 4th International Conference of cGMP Generators, Effectors and Therapeutic Implications

Regensburg, Germany. 19-21 June 2009

Published: II August 2009

BMC Pharmacology 2009, 9(Supp| I):S2 doi:I0.1 |86/I47|-22 I0-9-SI-S2

This abstract is available from: http://www.biomedcentral.com/I47I-22I0/9/SI/S2

(c) 2009 McRobert et al; licensee BioMed Central Ltd.

The life cycle of the malaria parasite Plasmodium is complex with distinct phases occurring in the human host and the mosquito vector. Proliferation of asexual parasites within blood cells leads to pathology whereas a distinct sexual stage is required to mediate transmission to the insect. There is a surprising lack of information about how progression of the life cycle is controlled. By analogy with other systems, it is likely that differentiation is regulated by intracellular signalling cascades involving specific phosphorylation/dephosphorylation events. Following an early report in the literature suggesting a role for the parasite cGMP signalling pathway in male gametogenesis, our recent work has investigated the role of the P. falciparum cGMP-dependent protein kinase (PfPKG) in the parasite life cycle. We have used specific inhibitors of the parasite PKG in conjunction with transgenic parasites expressing an inhibitor-insensitive PfPKG to provide direct evidence of a role for this kinase in gametogenesis [1]. Furthermore, we have used this approach recently to elucidate a central role for PfPKG in the late events of $P$. falciparum asexual blood stage schizogony. Using the $P$. berghei mouse malaria model we have also demonstrated a role for the kinase in gliding motility of the ookinete; the zygote form that borrows through the insect midgut wall.
Discovery of essential functions for PfPKG in multiple developmental stages suggest that it may be a good target for new anti-malarial drugs.

\section{References}

I. McRobert, Taylor C], Deng W, Fivelman QL, Cummings RM, Polley $\mathrm{SD}$, Billker O, Baker DA: Gametogenesis in malaria parasites is mediated by the cGMP-dependent protein kinase. PLoS Biol 2008, 6:el39. 